\title{
Implementasi Model Sfae Untuk Peningkatan Kemampuan Komunikasi dan Simulasi Matematika pada Mahasiswa PGSD FIP Undiksha
}

\author{
I Made Suarjana \\ Universitas Pendidikan Ganesha \\ email: suarjana_undiksha.@yahoo.co.id
}

\begin{abstract}
Abstrak
Penelitian ini bertujuan untuk (1) mengetahui kemampuan komunikasi dan simulasi matematika mahasiswa setelah diterapkan pembelajaran model SFAE pada mata kuliah Pendidikan Matematika di Kelas Tinggi dan (2) Kendala-kendala yang dialami mahasiswa dalam penerapan komunikasi dan simulasi matematika dalam pembelajaran. Penelitian ini dilaksanakan pada mahasiswa semester IV kelas F PGSD FIP Undiksha. Penelitian ini dilakukan di Prodi PGSD FIP Undiksha. Penerapan pembelajaran berbasis SFAE dilakukan setelah mahasiswa mengikuti tes tengah semester (TTS). Hasil tes sebelum penerapan perangkat pembelajaran berbasis SFAE rata-rata 77.20 Setelah diterapkan perangkat pembelajaran berbasis SFAE maka dilakukan tes akhir semester (TAS) diperoleh hasil rata-rata 88.41. Hasil TTS dan TAS menunjukkan adanya peningkatan dari sebelum penerapan perangkat berbasis SFAE dengan setelah penerapan perangkat berbasis SFAE. Hasil komunikasi dan simulasi matematika mahasiswa memperoleh rata-rata 79.32.
\end{abstract}

Kata kunci: SFAE, komunikasi, matematika, simulasi

\begin{abstract}
Abstrack
This study aims to (1) determine the design of RPS based on SFAE model of Mathematics Education II subject in order to improve communication skills and mathematical simulation for the students, and (2) determine the practicality of RPS based on SFAE model of Mathematics Education II subjects in order to improve communication skills and mathematical simulation RPS based on SFAE model of Mathematics Education II subjects in lecturing. The research was conducted in the fourth semester student of class $C$ and D of PGSD FIP Undiksha. The development of this study refers to the scheme on the implementation stages of evaluation model analysis, design, development, implementation, and evaluation (ADDIE). This research was conducted at the Department of PGSD FIP Undiksha. The data collection was done through observation, interviews and tests. To assess the design of RPS SFAE models of Education Mathematics II, the data analysis was done through descriptive-qualitative. The result of the design or systematic syllabus, RPS, and lecture contract of Lesson Plan SFAE based, was obtained score 80 or in the good category. With the score of 80 the draft of lesson plan that has arranged needs improvement or revision as necessary of some components. Based on the expert's assessment of the practicality of the learning device was obtained score 85 or in a good category. The implementation of learning SFAE based was done after the students took the midterm test (TTS). The results of the test before the application of learning SFAE based earned the average 77.20. After applied the learning device SFAE based then conducted final tests semester (TAS) obtained the average of 88.41. The results of TTS and TAS showed that there was an increase on the prior application device of SFAE based and after the application devices of SFAE based. The results of students' communication and mathematical simulation earned the average of 79.32 .
\end{abstract}

Keywords: SFAE, communication, mathematics, simulation,

\section{Pendahuluan}

Sejalan dengan implemetasi Permen tersebut, sejak tahun akademik 2016/2017 Undiksha menerapkan kurikulum berbasis Kerangka Kualifikasi Nasioanl Indonesia (KKNI). Kompetensi lulusan PGSD disesuaikan dengan profil dan capaian pembelajaran atau learning outcame, serta visi dan misi Jurusan. Visi Jurusan PGSD adalah terwujudnya program studi yang unggul dalam mengembangkan ilmu pengetahuan dan teknologi dalam bidang Pendidikan Guru Sekolah Dasar dengan berlandaskan falsafah Tri Hita Karana, serta misi Jurusan PGSD poin a adalah menyelenggarakan pendidikan dan pengajaran untuk menghasilkan sumber daya manusia yang berkualitas tinggi di bidang PGSD (Pedoman Studi, 2016). Untuk mewujudkan visi dan misi tersebut maka salah satu yang perlu ditingkatkan adalah standar proses perkuliahan. Dalam perkuliahan hendaknya mahasiswa tidak hanya dijejali teori hampa dan abstrak namun teori disertai dengan praktek nyata. Praktek nyata bisa langsung di lapangan maupun melalaui simulasi. Ini tentu diperlukan persiapan sistematis yang dituangkan dalam RPS. Dengan RPS yang sistematis diharapkan dosen bisa melaksanakan pembelajaran dengan efektif, kreatif, inovatif, dan menyenangkan.

Pengembangan RPS hendaknya disesuaikan dengan kondisi di lapangan. Selama ini input mahasiswa PGSD sangat beragam, ada dari SMA dan SMK. Sistem penerimaan mahasiswa juga beragam, ada melalui jalur undangan, jalur Sistem Bersama Masuk Perguruan Tinggi Negeri (SBMPTN), dan jalur Penerimaan Mahasiswa 
Jalur Lokal (PMJL). Keberagaman mahasiswa tersebut menunjukkan juga keberagaman kemampuan mahasiswa. Oleh karena itu, diperlukan strategi yang tepat dan inovatif dalam pembelajaran berjalan dengan lebih efektif. Di lain pihak, berdasarkan data hasil angket kinerja dosen satu tahun terakhir menunjukkan bahwa kinerja dosen yang mengajar di PGSD menunjukkan: kinerja menutun, jarang memanfaatkan ICT, kurang inovatif, beberapa dosen belum menyiapkan RPS dalam perkuliahan, dan penilaiannya masih dominan menilai hasil. Hal tersebut menyebabkan mahasiswa kurang kreatif dan belum maksimal dalam mengkomunikasikan dan simulasi konsepkonsep matematika dalam pembelajaran matematika.

Berdasarkan fakta-fakta tersebut, diperlukan suatu solusi pembelajaran yang dapat menciptakan pembelajaran yang interaktif, memfasilitasi mahasiswa dalam belajar, dan melibatkan peran aktif mahasiswa, sehingga memantapkan penguasaan dan pemahaman mahasiswa dalam meningkatkan komunikasi dan simulasi pembelajaran Matematika. Salah satu model pembelajaran yang relevan diterapkan untuk meningkatkan komunikasi dan simulasi pembelajaran matematika tersebut adalah model pembelajaran SFAE (Student Fasilitator and Explaining). Model pembelajaran SFAE merupakan salah satu model yang inovatif. Model pembelajaran ini merupakan salah satu solusi dalam pengelolaan kelas berbasis mahasiswa aktif, memacu motivasi mahasiswa dan meningkatkan daya serap mahasiswa dengan melakukan demonstrasi. Kurniasih \& Berlin (2015:789) mengartikan model pembelajaran SFAE merupakan "model pembelajaran yang melatih siswa untuk dapat mempersentasikan ide tau gagasan mereka pada teman-temannya". Model pembelajaran ini akan relevan apabila mahasiswa secara aktif ikut serta dalam merancang materi pembelajaran yang akan dipresentasikan atau disimulasikan. Lima fase pembelajaran yang diterapkan pada penerapan RPS berbasis SFAE seperti Tabel 1.

Tabel 1. Fase pembelajaran $S F A E$

\begin{tabular}{clc}
\hline No & \multicolumn{3}{c}{ Fase Pembelajaran } \\
\hline 1 & $\begin{array}{l}\text { Dosen menyampaikan kompetensi atau tujuan } \\
\text { perkuliahan. }\end{array}$ \\
2 & $\begin{array}{l}\text { Dosen meminta mahasiswa untuk mengkaji } \\
\text { konsep/materi dan menyusun } \\
\text { pembelajaran untuk simulasi. }\end{array}$
\end{tabular}

3 Mahasiswa melakukan simulasi pembelajaran sesuai dengan rencana yang telah disusun.

4 Mahasiswa dan dosen memberi tanggapan terhadap simulasi yang dilakukan oleh mahasiswa.

5 Mahasiswa menyimpulkan materi dibimbing dosen dan menutup perkuliahan. Aktivitas Pembelajaran Berdoa, absensi, menyiapkan pembelajaran, apersepsi, penyampaian tujuan pembelajaran Mahasiswa mengkaji materi atau konsep ditinjau dari berbagai refrensi difasilitasi oleh dosen. Hasil kajian tersebut dipakai acuan menyusun RPS bahan presentasi atau simulasi.

Mahasiswa melakukan presentasi/simulasi materi berkaitan dengan pembelajaran matematika.

Selesai mahasiswa simulasi, mahasiswa lain memberikan pertanyaan, tanggapan, atau saran difasilitasi oleh dosen.

Mahasiswa menyimpulkan materi, refleksi, evaluasi, dan tindak lanjut difasilitasi oleh dosen.

Suatu model pembelajaran memiliki kelebihan dan kekurangan. Huda (2013) menyatakan kelebihan model pembelajaran SFAE adalah 1) membuat materi yang disampaikan lebih jelas dan konkret, 2) meningkatkan daya serap siswa karena pembelajaran dilakukan dengan demonstrasi, 3) melatih siswa untuk menjadi guru, 4) memacu motivasi siswa untuk menjadi yang terbaik dalam menjelaskan materi ajar, dan 5) mengetahui kemampuan siswa dalam menyampaikan ide atau gagasan. Kekurangan pada model ini yaitu (1) adanya pendapat yang sama sehingga hanya sebagian saja yang tampil, dan (2) pengelolaan kelas masih sulit (Marcelina, 2013). Demikian juga Shoimin (2014:185) menyatakan kekurangan model SFAE adalah "1) siswa yang malu tidak mau mendemonstrasikan apa yang diperintahkan oleh guru kepadanya atau banyak siswa yang kurang aktif, 2) tidak semua siswa memiliki kesempatan yang sama untuk melakukannya atau menjelaskan kembali kepada teman-temannya karena keterbatasan waktu pembelajaran, 3) adanya pendapat yang sama sehingga hanya sebagian saja yang tampil, dan 4) tidak mudah bagi siswa untuk membuat peta konsep atau menerangkan materi ajar secara ringkas". Untuk meminimalisir kekurangan atau kelemahan model ini, maka dalam perkuliahan strategi yang perlu dilakukan yaitu: 1) memberi kesempatan kepada mahasiswa yang sudah siap untuk tampil pertama, sehingga mahasiswa yang malu dapat melihat temannya simulasi lebih awal, 2) setiap mahasiswa diberi kesempatan untuk tampil simulasi dengan memberi lebih awal materi yang akan disimulasikan, 3) mahasiswa diberi waktu yang cukup untuk mempersiapkan simulasi dan diberi bimbingan secukupnya sebelum simulasi, 4) dosen memberikan pemodelan pembelajaran sebelum mahasiswa membuat rancangan simulasi.

Proses pembelajaran tidak terlepas dari komunikasi karena komunikasi merupakan suatu proses penyampaian informasi atau ide-ide kepada orang lain. Penguasaan komunikasi yang baik oleh guru atau calon guru dapat membantu siswa dalam memahami dan mengeksplorasi matematika ke dalam konsep dan proses matematika yang mereka pelajari. Demikian juga dalam belajar matematika, kemampuan komunikasi guru sangat penting dan bermanfaat dalam proses pembelajaran matematika. Kusumah (dikutip Jazuli, 2009) menyatakan bahwa komunikasi merupakan bagian yang sangat penting dalam pembelajaran matematika. 
Pentingnya komunikasi matematis juga dikemukakan oleh Peressini dan Bassett (dikutip Izzati dan Suryadi, 2010) bahwa tanpa komunikasi dalam matematika kita akan memiliki sedikit keterangan, data, dan fakta tentang pemahaman siswa dalam melakukan proses dan aplikasi matematika. Menurut Guerreiro (dikutip Izzati dan Suryadi, 2010) menyebutkan bahwa komunikasi matematik merupakan alat bantu dalam transmisi pengetahuan matematika atau sebagai pondasi dalam membangun pengetahuan matematika. Selain itu, Lindquist (dikutip Izzati dan Suryadi, 2010) mengemukakan jika kita sepakat bahwa matematika itu merupakan suatu bahasa dan bahasa tersebut sebagai bahasa terbaik dalam komunitasnya, maka mudah dipahami bahwa komunikasi merupakan esensi dari mengajar, belajar, dan meng-assess matematika. Dari kedua pendapat ini, bahwa komunikasi merupakan alat bantu berupa bahasa yang sangat diperlukan dan penting dalam proses pembelajaran, karena tanpa komunikasi matematis maka proses pembelajaran tidak dapat terjadi.

Komunikasi bisa terjadi baik secara lisan, tulisan, kontak mata, bahasa tubuh, dan gambar. Melalui interaksi dalam simulasi, dapat diketahui kemampuan atau potensi setiap mahasiswa pada materi tersebut yang dilihat dari bagaimana mahasiswa tersebut menjelaskan, menjawab pertanyaan mahasiswa, dan dapat menginformasikan ide matematika kepada teman atau dosen. Melalui komunikasi, ide-ide dan gagasan menjadi objek-objek refleksi dan diskusi serta pemahaman. Dengan proses komunikasi dapat membantu membangun makna suatu gagasan untuk diketahui publik. Ada dua alasan penting yang dikemukakan oleh Baroody (dikutip Izzati dan Suryadi, 2010), mengapa komunikasi menjadi salah satu fokus dalam pembelajaran matematika. Pertama, matematika pada dasarnya adalah sebuah bahasa bagi matematika itu sendiri. Kedua, belajar dan mengajar matematika merupakan aktivitas sosial yang melibatkan paling sedikit dua pihak, yaitu pendidik dan peserta didik. Standar Komunikasi menitik beratkan pada pentingnya dapat berbicara, menulis, menggambarkan, dan menjelaskan konsep-konsep matematika. Menurut Van De Walle (2008, 4-5), belajar berkomunikasi dalam matematika membantu perkembangan interaksi dan pengungkapan ide-ide di dalam kelas karena siswa belajar dalam suasana yang aktif. Ketika anak-anak berpikir, menanggapi, membahas, menulis, membaca, mendengarkan, dan menanyakan tentang konsep-konsep matematika, mereka menuai manfaat ganda: mereka berkomunikasi untuk belajar matematika, dan mereka belajar untuk berkomunikasi matematis (NCTM, 2000). Menurut Barton (2008,152), ide-ide matematika yang akan dikomunikasikan harus sistematis, sehingga matematika dihasilkan. Hal ini yang menyebabkan mengapa matematika dan bahasa harus berkembang bersama.

Bertitik tolak dari paparan tersebut maka penerapan RPS berbasis Model SFAE sangat relevan dalam pembelajaran Pendidikan Matematika II. Melalui model ini mahasiswa diharapkan mampu mengkomunikasikan dan menguasai konsep-konsep matematika melalui simulasi pembelajaran matematika SD, selanjutnya dapat memberdayakan mahasiswa agar siap mengajar matematika di SD. Huda (2013:228), menyatakan bahwa "bagaimana guru mampu menyajikan atau mendemonstrasikan materi di depan siswa lalu memberikan mereka kesempatan untuk menjelaskan kepada teman-temannya" dalam hal ini mahasiswa dituntut mampu mengkomunikasikan matematika kepada temannya. Oleh karena itu, tujuan penelitian (1) untuk mengetahui rancang bangun RPS model SFAE mata kuliah Pendidikan Matematika II dalam rangka meningkatkan kemampuan komunikasi dan simulasi matematika mahasiswa, dan (2) untuk mengetahui kemampuan komunikasi dan simulasi matematika mahasiswa setelah diterapkan RPS model SFAE mata kuliah Pendidikan Matematika II dalam perkuliahan.

\section{Metode Penelitian}

Penelitian ini dilaksanakan pada mahasiswa semester IV kelas C dan D PGSD FIP Undiksha. Kelas C banyak mahasiswa 37 tahun dan kelas D banyak mahasiswanya 33 orang. Rencana pengembangan penelitian ini mengacu pada skema mengenai tahapan-tahapan pelaksanaan evaluasi model analysis, design, development, implementation, dan evaluation (ADDIE). Tahapan model ADDIE (Tegeh, dkk. 2014) dapat diketahui seperti Gambar 1.

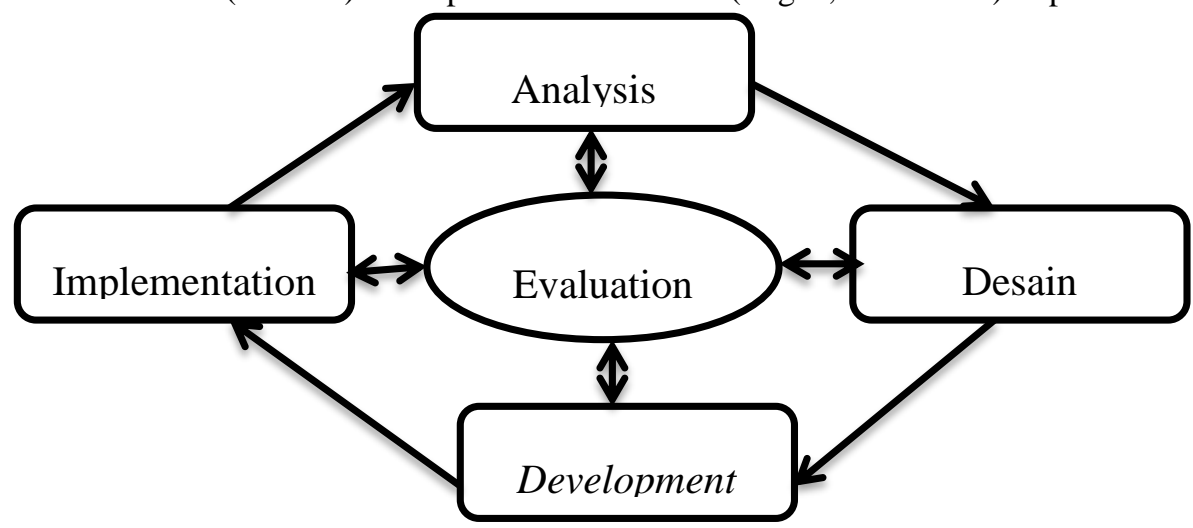

Gambar 1. Tahapan Model ADDIE 
Pengembangan model ADDIE (1) Analisis (Analysis) merupakan tahap pertama yang harus dilakukan oleh seorang pengembang pembelajaran. Langkah analisis dilakukan untuk mengetahui dan mengklarifikasi apakah kompetensi mahasiswa perlu peningkatan atau perbaikan. Pada penelitian ini, analisis kinerja: kurangnya pengetahuan mahasiswa pada komunikasi dan simulasi mahasiswa dalam pendidikan matematika, (2) perancangan (Design) dilakukan untuk menyusun rancang bangun RPS dan perangkat pendukungnya. Perancangan RPS perlu diperhatikan: (a) karakteristik mahasiswa, (b) tuntutan kemampuan yang ingin dicapai mahasiswa, (c) strategi pembelajarannya, dan (d) menentukan bentuk dan metode asesmen dan evaluasi yang digunakan, (3) Pengembangan (Development), kegiatan yang dilakukan adalah menerjemahkan spesifikasi desain ke dalam bentuk fisik, sehingga menghasilkan prototype produk pengembangan (Tegeh, dkk, 2014). Kegiatan tahap pengembangan adalah: pengumpulan sumber belajar/materi yang dibutuhkan, penyusunan rancang bangun RPS, menyusun RPS dan kelengkapan pendukungnya, penyusunan instrument evaluasi, serta uji ahli, (4) implementasi (Implementation), prototype RPS yang telah dikembangkan sedemikian rupa sesuai dengan peran atau fungsinya agar bisa diimplementasikan. Tujuan langkah ini antara lain: 1) membimbing mahasiswa untuk mencapai tujuan atau kompetensi, 2) menjamin terjadinya pemecahan masalah/solusi untuk dihadapi oleh mahasiswa, 3) memastikan bahwa pada akhir program pembelajaran, siswa perlu memilki kompetensi pengetahuan, ketrampilan, dan sikap yang diperlukan, dan (4) Evaluasi (Evaluation), proses untuk melihat apakah sistem pembelajaran yang sedang dibangun berhasil, sesuai dengan harapan awal atau tidak. Evaluasi terhadap program pembelajaran bertujuan untuk mengetahui beberapa hal, yaitu: 1) sikap mahasiswa terhadap kegiatan pembelajaran secara keseluruhan, 2) peningkatan kompetensi dalam diri siswa, yang merupakan dampak dari keikutsertaan dalam program pembelajaran, serta 3) keuntungan yang dirasakan oleh mahasiswa akibat adanya peningkatan kompetensi setelah mengikuti program pembelajaran. Implementasi desain RPS model SFAE pada perkuliahan Pendidikan Matematika II secara sistemik diharapkan dapat membantu seorang perancang program, dosen, dan instruktur dalam menciptakan program pembelajaran yang efektif, efisien, dan menarik.

Hasil penilaian perangkat rancang bangun RPS model SFAE Pendidikan Matematika II oleh uji ahli dan hasilnya dianalisis secara deskriptif-kualitatif. Menentukan kemampuan komunikasi dan simulasi pembelajaran matematika mahasiswa menggunakan rumus sebagai berikut.

$M=\frac{\sum f X}{\sum f}$

(Koyan, 2009)

Keterangan:

$\mathrm{M} \quad=$ Mean (rata-rata) skor

$\sum X=$ Jumlah hasil kali frekuensi dengan skor

$\sum f=$ jumlah seluruh frekuensi

Persentase komunikasi matematika mahasiswa secara klasikal dapat digunakan rumus sebagai berikut.

$$
M(\%)=\frac{M}{S M I} x 100 \% \quad \text { (Koyan, 2009) }
$$

Keterangan:

$\mathrm{M}(\%)=$ Rata-rata persen

$\mathrm{M} \quad=$ Rata-rata skor

SMI = Skor maksimal ideal

Kemampuan komunikasi matematika mahasiswa pada pelajaran matematika, dianalisis dengan membandingkan (M\%) atau persentase rata-rata hasil belajar mahasiswa ke dalam PAP skala 5. Model pembelajaran SFAE diharapkan dapat membantu mahasiswa dalam meningkatkan komunikasi dan simulasi pembelajaran Matematika. Model pembelajaran SFAE merupakan salah satu model yang inovatif dan diharapkan merupakan solusi dalam pengelolaan kelas berbasis siswa aktif, memacu motivasi siswa dan meningkatkan daya serap siswa dengan melakukan demonstrasi. Model pembelajaran ini akan relevan apabila mahasiswa secara aktif ikut serta dalam merancang materi pembelajaran yang akan dipresentasikan atau disimulasikan. Melalui model ini mahasiswa diharapkan mampu mengkomunikasikan dan melaksanakan pembelajaran matematika SD melalui simulasi, selanjutnya dapat memberdayakan mahasiswa agar siap mengajar matematika di SD.

\section{Hasil dan Pembahasan}

Penyiapan perangkat pembelajaran yang antara lain berupa silabus, rencana pembelajaran semester, maupun kontrak perkuliahan merupakan konsekwensi logis dari implementasi suatu kurikulum. Perangkat pembelajaran akan memberi arah bagi pengelola proses pembelajaran, bagaimana pembelajaran itu akan terjadi, 
dan ini merupakan dimensi kedua dari kurikulum yaitu berupa rancangan bagaimana cara yang digunakan untuk kegiatan pembelajaran (Panduan Pengembangan Kurikulum Undiksha, 2016).

Hasil uji rancangan sistematika silabus, Rencana Pembelajaran Semester (RPS), dan kontrak kuliah oleh ahli Rancangan Perangkat Pembelajaran yaitu Dr. I Made Tegeh, M.Pd, ternyata memperoleh skor 80 atau berada pada kategori baik. Dengan skor 80 rancangan perangkat pembelajaran yang disusun perlu adanya perbaikan atau revisi seperlunya beberapa komponen. Saran dari ahli adalah agar sistematika perangkat disesuaikan dengan pedoman kurikulum berbasis Kerangka Kualifikasi Nasional Indonesia (KKNI) yang disusun oleh Undiksha. Oleh karena itu diperoleh rancang bangun perangkat perkuliahan mata kuliah Pendidikan Matematika II adalah: (1) silabus mata kuliah, (2) RPS, dan (3) kontrak perkuliahan. Masing-masing komponen tersebut dirumuskan sebagai berikut.

Mengacu pada rancangbangun atau sistematika silabus, RPS, dan kontrak kuliah yang telah ditetapkan, maka untuk menilai kepraktisannya perlu disusun prangkat yang mudah dan bisa dimengerti oleh siapapun yang menggunakannya. Berdasarkan penilaian ahli perangkat pembelajaran ternyata memperoleh skor 85 atau kategori baik. Perangkat pembelajaran berbasis SFAE Pendidikan Matematika II yang telah disusun diterapkan dari bulan bulan April sampai dengan bulan Juni 2016 pada mahasiswa semester IV Kelas C dan D PGSD tahun 2015/2016 diperoleh hasil seperti tabel 2.

Tabel 2. Rata-Rata Hasil Tes Mahasiswa

\begin{tabular}{ccccccc}
\hline Kelas & \multicolumn{2}{c}{ Hasil Pre-test } & \multicolumn{2}{c}{ Pos- test (skala 100) } & \multicolumn{2}{c}{ Kemampuan Komunikasi } \\
& & & & & \multicolumn{2}{c}{ dan Simulasi Matematika } \\
& Skala 5 & Skala 8 & Skala 5 & Skala 8 & Skala 5 & Skala 8 \\
\hline C & $76.5(\mathrm{C})$ & $2,75\left(\mathrm{~B}^{-}\right)$ & 88.38 & $3.25(\mathrm{~B}+)$ & $78.42(\mathrm{C})$ & $2,75\left(\mathrm{~B}^{-}\right)$ \\
D & $77.89(\mathrm{C})$ & $2,75\left(\mathrm{~B}^{-}\right)$ & 88.44 & $3.25(\mathrm{~B}+)$ & $80.22(\mathrm{~B})$ & $2,75\left(\mathrm{~B}^{-}\right)$ \\
Rata-Rata & $77.20(\mathrm{C})$ & $2,75\left(\mathrm{~B}^{-}\right)$ & 88.41 & $3.25(\mathrm{~B}+)$ & $79.32(\mathrm{C})$ & $2,75\left(\mathrm{~B}^{-}\right)$ \\
\hline
\end{tabular}

Penerapan perangkat pembelajaran berbasis SFAE yang meliputi Silabus, RPS, Kontrak Kuliah mata kuliah Pendidikan Matematika II membawa dampak positif terhadap peningkatan hasil belajar mahasiswa. Ratarata hasil UTS mahasiswa adalah 77.20 (B-) dan UAS mahasiswa adalah 88. 41 (B+). Hal ini dapat terjadi karena ada kesesuaian antara tuntutan kurikulum PGSD dengan karakteristik SFAE. Pada kurikulum PGSD, tujuan pembelajaran matematika adalah mengomunikasikan gagasan dengan simbol, tabel, diagram atau media lain untuk memperjelas keadaan atau masalah dan melaksanakan simulasi matematika. Hal ini didukung oleh karakteristik model SFAE, yang dikemukakan oleh Kurniasih \& Berlin (2015) mengartikan model pembelajaran SFAE merupakan model pembelajaran yang melatih siswa untuk dapat mempresentasikan ide atau gagasan mereka pada teman-temannya. Model pembelajaran ini akan relevan apabila mahasiswa secara aktif ikut serta dalam merancang materi pembelajaran yang akan dipresentasikan. Selain itu, Shoimin (2014:183) menyatakan bahwa model pembelajaran $S F A E$ adalah "salah satu tipe pembelajaran kooperatif yang menekan pada struktur khusus yang dirancang untuk memengaruhi pola interaksi peserta didik dan memiliki tujuan untuk meningkatkan penguasaan materi". Kedua pendapat tersebut menunjukkan bahwa model pembelajaran SFAE adalah model pembelajaran yang membantu mahasiswa dalam memahami materi pembelajaran dengan meningkatkan kemampuan menjelaskan kepada teman lain serta meningkatkan motivasi dan keaktifan mahasiswa.

Model SFAE ini sangat cocok diterapkan dalam perkuliahan khususnya Pendidikan Matematika II, karena mata kuliah pada hakikatnya menuntut mahasiswa menguasai konsep matematika dan mampu mensimulasikan konsep tersebut kepada mahasiswa dengan efektif. Malatih mahasiswa pada dimensi mengkomunikasikan dan mensimulasikan materi matematika tentu akan memperkuat pengetahuan mereka dibandingkan hanya mendapat penjelasan dari orang lain. Huda (2013) menyatakan kelebihan model pembelajaran SFAE adalah: materi yang disampaikan lebih jelas dan konkret, meningkatkan daya serap mahasiswa karena pembelajaran dilakukan dengan demonstrasi, melatih mahasiswa untuk menjadi calon guru, memacu motivasi mahasiswa untuk menjadi yang terbaik dalam menjelaskan materi ajar, dan mengetahui kemampuan mahasiswa dalam menyampaikan ide atau gagasan.

Sebelum mahasiswa bersimulasi tentu mereka akan belajar dengan serius untuk mempersiapkan diri akan tampil secara optimal. Rambu-rambu materi dan rubrik untuk komunikasi dan simulasi matematika sudah dijelaskan terlebih dahulu dan dibagikan kepada mereka. Dengan demikian diharapkan mahasiswa dapat mempersiapkan diri dengan baik agar mendapat nilai optimal. Hasil observasi diperoleh rata-rata hasil komunikasi dan simulasi berada pada kategori cukup, hal ini bisa terjadi karena mahasiswa belum terbiasa dengan menjelaskan materi dalam bentuk komunikasi dan simulasi karena kemampuan pedagogic mereka belum optimal. Hal positif yang terjadi dalam proses pembelajaran adalah adanya interaksi antara mahasiswa, karena mereka diberi kesempatan untuk menanggapi hasil simulasi temannya yang telah tampil. Kemampuan mengajukan pertanyaan, kemampuan menyampaikan pendapat, kemampuan memberi tanggapan, atau komentarkomentar lainnya yang sangat banyak terjadi dari mahasiswa. Kalau ada pertanyaan atau kesulitan mahasiswa maka dosen berperan untuk memberikan masukan atau penjelasan hal-hal belum jelas. Dengan komunikasi dan simulasi ini mahasiswa merasa multi dimensi pengetahuan yang merasa mereka pelajari, berdasarkan komentar 
mahasiswa dalam simulasi banyak hal mesti dilakukan seperti misalnya mengelola kelas, menjelaskan materi, menggunakan alat peraga, mengajukan pertanyaan, menjawab pertanyaan teman, menulis symbol-simbol matematika dan sekaligus mengkomunikasikan symbol-simbol itu.

Oleh karena itu, agar perkuliahan berlangsung dengan efektif dan efisien maka perlu persiapan yang sistematis dengan penerapan model yang sesuai dengan tuntutan dari mata kuliah. Penyiapan perangkat pembelajaran berbasis SFAE yang sistematis dan sesuai dengan pedoman kurikulum berbaisis KKNI membawa dampak yang positif terhadap Pembelajaran pendidikan Matematika II. Perangkat RPS yang dikembangkan sudah praktis diterapkan karena secara terstruktur memuat capaian pembelajaran, rancangan pembelajaran, kontrak perkuliahan, aturan perkuliahan, soal-soal, serta dilengkapi dengan pedoman evaluasi.

\section{Simpulan}

Hasil uji rancangbangun atau sistematika silabus, RPS, dan kontrak kuliah Rancangan Perangkat Pembelajaran berbasis SFAE, ternyata memperoleh skor 80 atau berada pada kategori baik. Dengan skor 80 rancangan perangkat pembelajaran yang disusun perlu adanya perbaikan atau revisi seperlunya beberapa komponen. Saran dari ahli adalah agar sistematika perangkat disesuaikan dengan pedoman kurikulum berbasis KKNI yang disusun oleh Undiksha. Oleh karena itu diperoleh rancang bangun perangkat perkuliahan mata kuliah Pendidikan Matematika II adalah: (1) silabus mata kuliah, (2) rencana pembelajaran semester (RPS), dan (3) kontrak perkuliahan. Mengacu pada rancangbangun atau sistematika silabus, RPS, dan kontrak kuliah yang telah ditetapkan, maka untuk menilai kepraktisannya perlu disusun prangkat yang mudah dan bisa dimengerti oleh siapapun yang menggunakannya. Berdasarkan penilaian ahli perangkat pembelajaran ternyata memperoleh skor 85 atau kategori baik. Hasil revisi perangkat pembelajaran berbasis SFAE untuk diimplementasikan dalam perkuliahan Pendidikan Matenatika II memuat capaian pembelajaran, langkah-langkah pembelajaran, kontrak kuliah, aturan perkuliahan, soal-soal, dan pedoman evaluasi, sehingga siapapun dapat menerapkan perangkat inidengan baik. Hasil tes sebelum penerapan perangkat pembelajaran berbasis SFAE rata-rata 77.20, pada skala delapan 2,75 $\left(\mathrm{B}^{-}\right)$. Setelah diterapkan perangkat pembelajaran berbasis SFAE maka dilakukan UAS diperoleh hasil rata-rata 88.41, pada skala delapan adalah $3.25(\mathrm{~B}+)$. Hasil UTS dan UAS menunjukkan adanya peningkatan dari sebelum penerapan dan setelah penerapan perangkat RPS berbasis SFAE. Hasil komunikasi dan simulasi matematika mahasiswa memperoleh rata-rata 79.32 dan pada skala $2,75\left(\mathrm{~B}^{-}\right)$.

Dari Pembahasan tersebut dapat disaran kepada pengajar untuk menerapkan model SFAE dalam proses pembelajaran karena model ini sudah terbukti dapat meningkatkan Komunikasi dan simulasi matematika mahasiswa. Serta bagi peneliti karena model SFAE ini belum banyak digunakan di Sekolah Dasar maka disarankan untuk mencoba melakukan penelitian tentang model SFAE di sekolah dasar.

\section{Daftar Pustaka}

Hasbullah. 2012. Dasar-Dasar Ilmu Pendidikan. Jakarta: PT Raja Grafindo Persada

Huda, Miftahul. 2013. Model-model Pengajaran dan Pembelajaran: Isu-Isu Metodis dan Paradigmatis. Yogjakarta: Pustaka Pelajar.

Izzati,N \& Suryadi,D. (2010). Komunikasi matematik dan pendidikan matematika realistik. Makalah disampaikan dalam Seminar Nasional Matematika dan Pendidikan Matematika, pada tanggal 27 November 2010, di Yogyakarta.

Jazuli, Akhmad. (2009). Berfikir kreatif dalam kemampuan komunikasi matematika. Makalah disampaikan dalam Seminar Nasional, pada tanggal 5 Desember 2009, di Yogyakarta.

Jihad, Asep \& Abdul Haris. 2008. Evaluasi Pembelajaran. Yogjakarta: Multi Presindo.

Kadir. (2008). Kemampuan komunikasi matematik dan keterampilan sosial siswa dalam pembelajaran matematika. Makalah disampaikan dalam Seminar Matematika dan Pendidikan Matematika, pada tanggal 28 November 2008, di Yogyakarta.

Kurniasih, Imas \& Berlin Sani. 2015. Ragam Pengembangan Model Pembelajaran: Untuk Peningkatan Profesionalitas Guru. Jakarta: Kata Pena.

NCTM. (2000). Principles and Standards for School Mathematics. Tersedia : http://www.k12academics. com/education-reform. Diakses : 20 September 2011.

Permenristekdikti, Nomor 44 tahun 2015 tentang Standar Nasional Pendidikan Tinggi

Permendikbu No. 67 Tahun 2013 tentang Kerangka dasar dan Struktur Kurikulum SD.

Plomp, Tjeerd. 2013. Educational Design Research: an Introduction. In Tjeerd Plomp and Nienke Nieveen (Ed). An Introduction to Educational Design Research(hlm. 10-51) Netherlands: Netzodruk, Enschede an

Riedesel, Schwartz, dan Clements. 1996. Teaching Elementary School Mathematics. USA: Allyn and Bacon

Simon, M.A. 1995. Reconstructing Mathematics Pedagogy from a Construction Perspective. Jounal for Research in Mathematics Education. 26. 114-145

Suharta. 2011. Pemecahan Masalah Matematika Real pada siswa Sekolah Dasar (Studi Kasus pada Siswa SD No. 5 Penarukan dan SD No. 4 Kampung Baru). Hasil Penelitian tidak Diterbitkan. Singaraja: Undiksha.

Tegeh, I Made, Dr, M.Pd, dkk. 2014. Model Penelitian Pengembangan. Singaraja: Undiksha Press. 